\title{
Effective removal of lead (II) ions by dead calcareous skeletons: sorption performance and influencing factors
}

\begin{abstract}
Dead calcareous skeletons (CSs) as low-cost adsorbents were studied to remove lead ions $(\mathrm{Pb}$ (II)) in an aqueous solution. Factors influencing the efficiency of CSs were evaluated by adsorbent size, contact time, initial concentration, dosage concentration and $\mathrm{pH}$. The optimum CS size for removal of $\mathrm{Pb}$ (II) was $710 \mu \mathrm{m}$ at an equilibrium time of $720 \mathrm{~min}$. The best dosage of CS was $10 \mathrm{~g} / \mathrm{L}$ for a $99 \%$ removal efficiency without $\mathrm{pH}$ adjustment. $\mathrm{Pb}$ (II) ions were effectively removed in the initial $\mathrm{pH}$ of the metal solution. CS was able to remove a high concentration $(100 \mathrm{mg} / \mathrm{L})$ of $\mathrm{Pb}$ (II) at a removal efficiency of $99.92 \%$ and at an adsorption capacity of $13.06 \mathrm{mg} / \mathrm{g}$. Our results demonstrated the potential of CS as a metal adsorbent in the aqueous phase with a high-removal efficiency and distinct physical characteristics.
\end{abstract}

Keyword: Lead (II) ions; Dead calcareous skeletons; Sorption performance 